\title{
Correction to: Tizoxanide induces autophagy by inhibiting PI3K/ Akt/mTOR pathway in RAW264.7 macrophage cells
}

\author{
Jiaoqin Shou ${ }^{1,2} \cdot$ Mi Wang ${ }^{1} \cdot$ Xiaolei Cheng ${ }^{1} \cdot$ Xiaoyang Wang $^{1} \cdot$ Lifang Zhang $^{1} \cdot$ \\ Yingchun Liu $^{1}$ - Chenzhong Fei ${ }^{1}$ Chunmei Wang ${ }^{1} \cdot$ Feng Gu$^{1} \cdot$ Feiqun Xue $^{1}$. \\ Juan $\mathrm{Li}^{2} \cdot$ Keyu Zhang ${ }^{1}$
}

Published online: 24 February 2020

(c) The Pharmaceutical Society of Korea 2020

\section{Correction to: Arch. Pharm. Res. https://doi. org/10.1007/s12272-019-01202-4}

Unfortunately in the original publication of the article, the Fig. 2 was missed in the PDF version of the article which is given in this correction. The original article has been corrected.
The original article can be found online at https://doi. org/10.1007/s12272-019-01202-4.

Juan Li

juanli@xtu.edu.cn

Keyu Zhang

zcole@shvri.ac.cn

1 Key Laboratory of Veterinary Chemical Drugs and Pharmaceutics, Ministry of Agriculture and Rural Affairs, Shanghai Veterinary Research Institute, Chinese Academy of Agricultural Sciences, 518 Ziyue RD, Minhang District, Shanghai 200241, China

2 College of Chemistry, Xiangtan University, Yuhu District, Xiangtan 411105, Hunan, China
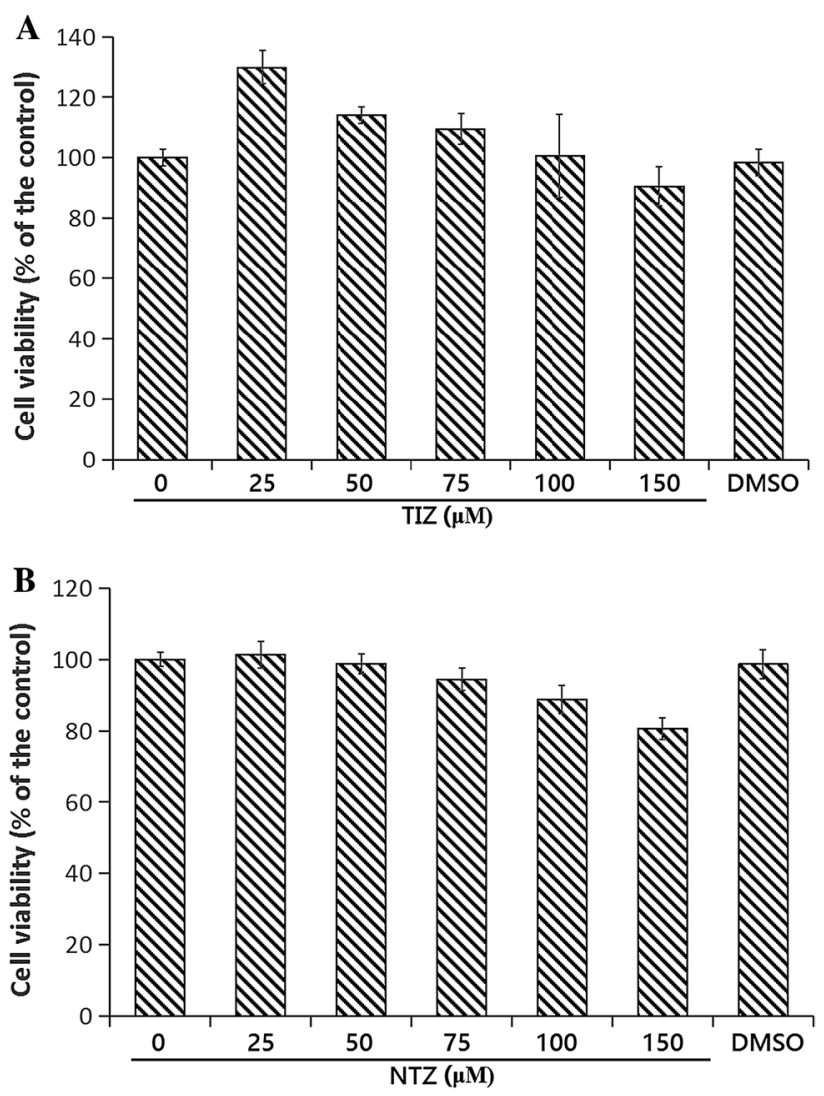

Fig. 2 Cytotoxicity of TIZ (a) and NTZ (b) on RAW264.7 cells. Cells were treated with TIZ at $25,50,75,100$, and $150 \mu \mathrm{M}$ for $12 \mathrm{~h}$, and cell viability was assayed by the CCK- 8 kit. The cell viability of macrophage treated with NTZ and TIZ at $150 \mu \mathrm{M}$ were resulted in significant decrease $(90.43 \%$ and $80.65 \%$, respectively). Data are expressed as the means \pm S.D. of three independent experiments

Publisher's Note Springer Nature remains neutral with regard to jurisdictional claims in published maps and institutional affiliations. 